\title{
BMJ Open Burn injury and long-term nervous system morbidity: a population-based cohort study
}

\author{
Thirthar P Vetrichevvel, ${ }^{1}$ Sean M Randall, ${ }^{2}$ Mark W Fear, ${ }^{1}$ Fiona M Wood, ${ }^{1,3}$ \\ James $\mathrm{H}$ Boyd, ${ }^{2}$ Janine M Duke ${ }^{1}$
}

To cite: Vetrichevvel TP, Randall SM, Fear MW, et al. Burn injury and long-term nervous system morbidity: a population-based cohort study. BMJ Open 2016;6: e012668. doi:10.1136/ bmjopen-2016-012668

- Prepublication history for this paper is available online. To view these files please visit the journal online (http://dx.doi.org/10.1136/ bmjopen-2016-012668).

Received 17 May 2016 Revised 27 July 2016 Accepted 16 August 2016

CrossMark

${ }^{1}$ Burn Injury Research Unit, School of Surgery, University of Western Australia, Perth, Western Australia, Australia ${ }^{2}$ Centre for Data Linkage, Curtin University, Perth, Western Australia, Australia ${ }^{3}$ Burns Service of Western Australia, Fiona Stanley Hospital and Princess Margaret Hospital, Perth, Western Australia, Australia

\section{Correspondence to} Professor Janine M Duke; janine.duke@uwa.edu.au

\section{ABSTRACT}

Objective: To investigate if children and adults who are hospitalised for a burn injury have increased longterm hospital use for nervous system diseases.

Design: A population-based retrospective cohort study using linked administrative health data from the Western Australian Data Linkage System.

Participants: Records of 30997 persons hospitalised for a first burn injury in Western Australia during the period 1980-2012, and 123399 persons who were age and gender frequency matched with no injury admissions randomly selected from Western Australia's birth registrations and electoral roll.

Main outcome measures: Admission rates and summed length of stay for nervous system diseases. Negative binomial and Cox proportional hazards regression modelling were used to generate incidence rate ratios (IRRs) and $\mathrm{HRs}$ with $95 \% \mathrm{Cls}$, respectively. Results: After adjustment for demographic factors and pre-existing health status, the burn injury cohort had 2.20 times ( $95 \% \mathrm{Cl} 1.86$ to 2.61 ) as many nervous system admissions and 3.25 times the number of days in hospital $(95 \% \mathrm{Cl}: 2.28$ to 4.64$)$ than the uninjured cohort. This increase was found for those who had sustained burns during childhood ( $<15$ years: IRR, $95 \% \mathrm{Cl}: 1.97,1.49$ to 2.61$)$ and early to midadulthood (15-45 years: IRR, 95\% Cl: 2.70, 2.06 to 3.55 ) and older adults ( $\geq 45$ years: IRR, $95 \% \mathrm{Cl}: 1.62$, 1.33 to 1.97 ). Significantly elevated first-time postburn admissions were observed for children for 15 years postburn discharge $(0-5$ years: HR, $95 \% \mathrm{Cl}: 1.97,1.75$ to 2.22 ; $5-15$ years: $\mathrm{HR}, 95 \% \mathrm{Cl}: 1.44,1.28$ to 1.63 ) and for adults 45 years and older at index burn for 5 years postburn only (HR, $95 \% \mathrm{Cl}: 1.72,1.42$ to 2.09 ).

Conclusions: Burn injury appears to be associated with increased nervous system-related morbidity for many years after burn injury. Further work into the mechanisms and possible treatments to reduce this morbidity are warranted in light of these findings.

\section{INTRODUCTION}

Long-term neuronal damage postburn injury is being increasingly identified. Systemic alterations in nerve fibre density, ${ }^{1}$ elevated levels of substance $\mathrm{P}$ positive nerve fibres (associated with pain and itch) in burn

\section{Strengths and limitations of this study}

- Contributes valuable information on long-term effects of minor and severe burns on the nervous system.

- Population-based cohort study using linked administrative data minimises issues of selection and reporting bias, and loss to follow-up.

- The retrospective longitudinal study design included a comparison group.

- Lack of individual-based risk factor data.

grafts, ${ }^{2}$ rapid and prolonged activation of microglial cells in the spinal cord, ${ }^{3}$ apoptosis in ventral horn motor neurons of the spinal cord $^{4}$ and increased brain tissue levels of tumour necrosis factor (TNF)- $\alpha$, interleukin (IL)- $1 \beta$ and IL- $6^{5}$ have all been identified postburn injury. However, the clinical implications of these changes for postburn morbidity remain unclear.

Sensory abnormalities in postburn scar have been studied extensively. Severe sensory deficit in touch, pressure and temperature sensation changes varying between $5 \%$ and $52 \%$ depending on the modality and depth of burn injury has been reported. ${ }^{6}$ Paraesthetic sensations including itching, warmth and coldness have been reported in different studies to be experienced by $10-87 \%$ of patients. ${ }^{6}{ }^{7}$ Chronic persistent pain after severe burn injury was reported by $52 \%$ of survey respondents, of which $55 \%$ reported interference with daily activities. ${ }^{8}$ The development of chronic pain is perceived to have a role of central and peripheral neuronal mechanisms. ${ }^{9}$ Electrodiagnostic studies using electromyography and motor nerve conduction velocities are more reflective of the physiology of the nerve and have shown features of polyneuropathy/mononeuropathy in 15-68\% of patients after burn injury, ${ }^{10-13}$ while clinical abnormalities have been reported in $\sim 10 \%$ 
of patients and related to the average burn surface area and aetiology of burn injury. ${ }^{14} 15$

Studies of the central nervous system (CNS) involvement in burn injuries have been restricted to effects in the acute stage. ${ }^{1617}$ There is also a dearth of studies identifying the effect of burn injury on pre-existing nervous system disorders in burn injury patients. In this study, population-based linked health administrative data were used to investigate if burn patients experienced increased longer term nervous system morbidity expressed in terms of hospital service use, when compared with an age-matched and gender frequencymatched cohort of individuals with no record of an injury admission.

\section{METHODS}

This study used data from the Western Australian Population-based Burn Injury Project (WAPBIP), a population-based retrospective cohort study established in 2014 using linked health records. The data were provided from the Western Australian Data Linkage System that links administrative health data routinely for the whole population of Western Australia; ${ }^{18}$ regular quality assessments of the data and links are undertaken. ${ }^{19}$ The project was approved by the Human Research Ethics Committees of the University of Western Australia and the Western Australian Department of Health. The WAPBIP project supports multiple studies and project methods have been previously published..$^{20-22}$

A de-identified extraction of all linked hospital morbidity records form the Hospital Morbidity Data System for all persons admitted to the hospital with an index burn injury in Western Australia, for the period from 1 January 1980 to 30 June 2012. The index burn injury was defined as the first hospital admission with a burn injury as the principal and/or additional diagnosis using the International Classification of Diseases (ICD) codes V.9 (ICD9-CM) 940-949 and V.10 (ICD10-AM) T20-T31. A population-based comparison cohort was randomly selected from the Western Australian birth registrations and electoral roll; any person with an injury hospitalisation during the study period was excluded from the noninjury cohort. The resultant uninjured comparison cohort was frequency matched on birth year (4:1) and gender of the burn injury cases for each year from 1980 to 2012 .

Hospital and death data were linked to each cohort (burn, non-injury) for the period 1980-2012. Hospital admissions data included principal and additional diagnoses, age and gender, indigenous status, admission and discharge dates, burn injury characteristics (total body surface area per cent (TBSA\%), depth and site) and residential postcode. TBSA\% was classified as minor $(\mathrm{TBSA}<20 \%)$, severe $(\mathrm{TBSA} \geq 20 \%)$ and unspecified TBSA\%. Indices of social disadvantage (least to most disadvantaged) ${ }^{23}$ and residential remoteness (major cities, inner regional, outer regional, remote and very remote) ${ }^{24}$ derived from the national census data were supplied for both cohorts. A variable to identify baseline comorbidity (yes/no) was generated using the Charlson comorbidity index ${ }^{25}$ with principal and additional diagnosis hospital data and a 5 -year look back period. ${ }^{26}$ Mortality data included the date and cause of death. Admissions for diseases of the nervous system were identified using principal diagnosis data and defined by codes within ICD Chapter 6 (ICD10: G00-G99); ICD9 codes were mapped to ICD10 codes. ${ }^{27}$

The total number of years a person was at risk (person-years) was estimated from the final discharge date for the burn cases and this date was used for the respective frequency-matched non-injury controls. Categorical and non-parametric continuous variables were compared using $\chi^{2}$ and Kruskal-Wallis tests, respectively, with a statistical significance level of $5 \%$.

The number of postburn admissions and summed length of stay for combined (G00-G99) and selected subgroups of nervous system diseases (G40-G47: episodic and paroxysmal disorders; G50-G59: nerve, nerve root and plexus disorders; and G60-G64: polyneuropathies and other peripheral nervous system disorders) were used as outcome measures. The admission of the index burn was not included in these outcomes. Crude yearly admission rates were calculated for these variables. Adjusted rate ratios were calculated using negative binomial regression. Sociodemographic (gender, indigenous, 5-year age group, social disadvantage, remoteness), year of admission (to adjust for temporal changes in treatments and referral patterns) and health status variables (baseline comorbidity, previous nervous system disease admission) were included as covariates in the models. Analyses were undertaken on the total burn and uninjured cohorts and subcohorts defined by gender and age at study start $(<15,15-45$ and $\geq 45$ years $)$.

Cox proportional hazards models were used to assess admission rates for first-time hospital use for nervous system diseases after burn discharge and models were adjusted for demographic and health covariates. Analyses were performed on the cohorts excluding those with a previous admission for a nervous system condition, and also excluding those in the burn cohort with a record of a non-burn injury admission to avoid potential confounding from non-burn injury-related systemic effects. ${ }^{28}$ The proportional hazard assumption for the burn injured versus non-injured was tested ${ }^{29}$ and if preliminary results showed non-proportionality, adjusted HRs were modelled for time periods guided by Aalen's linear hazard models and graphs. ${ }^{30}$

Attributable risk percentages $(\mathrm{AR} \%)$ were calculated as the adjusted rate ratio (HR) minus one, divided by the adjusted rate ratio (HR), multiplied by $100 .{ }^{31} \mathrm{AR} \%$ was used to estimate the proportion of incident admissions for diseases of the nervous system where burn injury was a component cause. ${ }^{32}{ }^{33}$ Statistical analyses were performed using Stata V.12 (StataCorp. LP, College Station, Texas, USA). 


\section{RESULTS}

\section{Cohort characteristics}

The burn cohort comprised 30997 individuals hospitalised with a first burn injury and the uninjured cohort comprised 123399 individuals age and gender frequency matched to burn cases. Over the 33-year study period, the burn and uninjured cohorts contributed a total of 485707 and 2009370 person-years of observation, respectively, with median years of follow-up (IQR) by age group for burn versus non-injured: younger than 15 years, $18.1 \quad(10.3-25.6)$ vs $17.9 \quad(10.2-25.5)$; $15-$ 45 years, $16.7(8.4-25.0)$ vs $16.7(8.8-25.0)$; 45 years and older, $9.0(3.0-16.0)$ vs $13.0(6.0-23.0)$.
The percentage of men in the burn $(n=21223)$ and the non-injured $(n=82875)$ cohort was $68 \%$ and the median age for both cohorts was 23 years with IQR 7-39 years. Refer to table 1 for a summary of sociodemographic and health status characteristics. The burn cohort had significantly higher proportions of those who were of indigenous status, from regional and remote areas, people who were socially disadvantaged, had pre-existing comorbidity and prior admission for nervous system disorders, when compared with the noninjury cohort. A third of the burn cohort $(\mathrm{n}=10351)$ had a record of non-burn injury admission over the study period (preindex or postindex burn).

Table 1 Demographic and health characteristics of the burn and non-injury cohorts

\begin{tabular}{|c|c|c|c|}
\hline Characteristics & $\begin{array}{l}\text { No injury } \\
\mathrm{N}(\%)\end{array}$ & $\begin{array}{l}\text { Burn injury } \\
\mathrm{N}(\%)\end{array}$ & p Value \\
\hline Total & 123399 & 30997 & \\
\hline \multicolumn{4}{|l|}{ Demographic } \\
\hline Indigenous status (yes) & $2993(2.4)$ & $4481(14.5)$ & $<0.001$ \\
\hline \multicolumn{4}{|l|}{ Social disadvantage quintiles ${ }^{*}$} \\
\hline Quintile 1 (most disadvantaged) & $14597(12.0)$ & $6579(21.6)$ & $<0.001$ \\
\hline Quintile 2 & $28339(23.4)$ & $9878(32.4)$ & \\
\hline Quintile 3 & $22142(18.2)$ & $6354(20.8)$ & \\
\hline Quintile 4 & 21671 (17.9) & $3833(12.6)$ & \\
\hline Quintile 5 (least disadvantaged) & 34609 (28.5) & 3857 (12.6) & \\
\hline \multicolumn{4}{|l|}{ Remotenesst } \\
\hline Major city & $88278(72.8)$ & $15810(51.7)$ & $<0.001$ \\
\hline Inner regional & $11725(9.7)$ & $3360(11.0)$ & \\
\hline Outer regional & $11653(9.6)$ & 4958 (16.2) & \\
\hline Remote & $5897(4.9)$ & 3434 (11.2) & \\
\hline Very remote & $3697(3.0)$ & $3011(9.8)$ & \\
\hline \multicolumn{4}{|l|}{ Health status } \\
\hline Any comorbidity $\ddagger$ & 4691 (3.8) & $3131(10.1)$ & $<0.001$ \\
\hline Prior admission for nervous system disease $§$ & $1474(1.2)$ & $1732(5.6)$ & $<0.001$ \\
\hline \multicolumn{4}{|l|}{ Burn injury characteristics } \\
\hline \multicolumn{4}{|l|}{$\%$ TBSA } \\
\hline$<20 \%$ minor & & $14854(48)$ & \\
\hline$\geq 20 \%$ severe & & $911(3)$ & \\
\hline Unspecified & & $15232(49)$ & \\
\hline \multicolumn{4}{|l|}{ Burn depthๆ } \\
\hline Full thickness & & 4390 (14) & \\
\hline Partial thickness & & $12307(40)$ & \\
\hline Erythema & & $5335(17)$ & \\
\hline Unspecified & & 9609 (31) & \\
\hline \multicolumn{4}{|l|}{ Siteף } \\
\hline Head and neck & & $6386(21)$ & \\
\hline Trunk & & 7262 (23) & \\
\hline Upper limbs/hands & & $13144(42)$ & \\
\hline Lower limbs/feet & & $10537(34)$ & \\
\hline Eyes & & $2303(7)$ & \\
\hline Respiratory tract or other internal organs & & $624(2)$ & \\
\hline Multiple sites & & $1237(4)$ & \\
\hline Unspecified site & & 904 (3) & \\
\hline
\end{tabular}

*SEIFA socio-economic disadvantage quintiles; missing values $1.3 \%$ burn, $1.7 \%$ no injury. TARIA+remoteness classification; missing values $1.4 \%$ burn, $1.8 \%$ no injury.

$\ddagger$ Any comorbidity based on Charlson comorbidity index with a 5 -year look-back period.

$\S$ Principal diagnosis admission for nervous system disease with a 5-year look-back period.

ๆMultiple burn sites and depths may be coded.

ARIA, Accessibility/Remoteness Index for Australia; SEIFA, socio-economic indexes for areas; TBSA, total body surface area. 
Examination of length of hospital stay (median, IQR days) for the first burn admission suggested the high likelihood that those with unspecified TBSA $(3,1-10)$ were misclassified $0-10 \%$ TBSA burns $(0-10 \%$ TBSA: 3, 1-9; 10-20\% TBSA: 11, 4-19; 20-50\% TBSA: 22, 11-39; 50-100\% TBSA: 72, 38-118).

\section{Admission rates and length of stay}

There were a total of 6121 hospital admissions occurring after burn discharge with a primary diagnosis of a

Table 2 Number of postburn discharge admissions (\%) for NS subconditions for the burn and non-injury cohorts

\begin{tabular}{|c|c|c|}
\hline \multirow[b]{2}{*}{ NS conditions } & \multicolumn{2}{|c|}{$\begin{array}{l}\text { Number of admissions } \\
\mathrm{N}(\%)\end{array}$} \\
\hline & No injury & $\begin{array}{l}\text { Burn } \\
\text { injury }\end{array}$ \\
\hline Total & $7311(100)$ & $6121(100)$ \\
\hline Inflammatory diseases of CNS & $98(1.3)$ & 77 (1.3) \\
\hline $\begin{array}{l}\text { Systemic atrophies primarily } \\
\text { affecting CNS }\end{array}$ & $79(1.1)$ & $42(0.7)$ \\
\hline $\begin{array}{l}\text { Extrapyramidal and movement } \\
\text { disorders }\end{array}$ & $172(2.4)$ & $117(1.9)$ \\
\hline $\begin{array}{l}\text { Other degenerative diseases } \\
\text { of NS }\end{array}$ & $171(2.3)$ & $98(1.6)$ \\
\hline $\begin{array}{l}\text { Demyelinating diseases of the } \\
\text { CNS }\end{array}$ & $721(9.9)$ & $214(3.5)$ \\
\hline $\begin{array}{l}\text { Episodic and paroxysmal } \\
\text { disorders }\end{array}$ & $2830(38.7)$ & $3814(62$ \\
\hline $\begin{array}{l}\text { Epilepsy and recurrent } \\
\text { seizures }\end{array}$ & $417(5.7)$ & $2589(42$. \\
\hline $\begin{array}{l}\text { Migraine, other headache } \\
\text { symptoms }\end{array}$ & $336(4.6)$ & $418(6.8)$ \\
\hline $\begin{array}{l}\text { Transient cerebral ischaemic } \\
\text { attacks and related syndromes }\end{array}$ & $503(6.9)$ & 201 (3.3) \\
\hline Sleep disorders & $1503(20.6)$ & $400(6.5)$ \\
\hline $\begin{array}{l}\text { Nerve, nerve root and plexus } \\
\text { disorders }\end{array}$ & $2049(28.0)$ & $918(15.0$ \\
\hline $\begin{array}{l}\text { Disorders trigeminal, facial and } \\
\text { cranial nerve }\end{array}$ & $100(1.4)$ & $55(0.9)$ \\
\hline $\begin{array}{l}\text { Nerve root and plexus } \\
\text { disorders }\end{array}$ & $27(0.4)$ & $48(0.8)$ \\
\hline $\begin{array}{l}\text { Mononeuropathy upper/lower } \\
\text { limbs }\end{array}$ & $1890(25.9)$ & $745(12$. \\
\hline Other mononeuropathies & $31(0.4)$ & $70(1.1)$ \\
\hline $\begin{array}{l}\text { Polyneuropathies, peripheral } \\
\text { NS disorders }\end{array}$ & $760(10.4)$ & $374(6.1)$ \\
\hline $\begin{array}{l}\text { Hereditary and idiopathic } \\
\text { neuropathy }\end{array}$ & $149(2.0)$ & $7(0.1)$ \\
\hline Inflammatory polyneuropathy & $405(5.5)$ & $276(4.5)$ \\
\hline $\begin{array}{l}\text { Other and unspecified } \\
\text { polyneuropathies }\end{array}$ & $206(2.8)$ & $91(1.5)$ \\
\hline $\begin{array}{l}\text { Myoneural junction and muscle } \\
\text { diseases }\end{array}$ & $32(0.4)$ & $23(0.4)$ \\
\hline $\begin{array}{l}\text { Cerebral palsy, other paralytic } \\
\text { syndromes }\end{array}$ & $105(1.4)$ & $120(2.0)$ \\
\hline Other disorders NS & $294(4.0)$ & $324(5.3)$ \\
\hline
\end{tabular}

Italicised-subconditions.

CNS, central nervous system; NS, nervous system. nervous system disease. Overall, $7.3 \%$ of the burn cohort had a postburn nervous system admission $(6.4 \%$ had 3 or less admissions; $0.4 \%>10$ admissions). The number (\%) of admissions by specific subconditions is shown in table 2. Admissions for episodic and paroxysmal disorders accounted for almost two-thirds of total postburn nervous system admissions.

A total of 38159 days were spent in hospital with a nervous system condition after hospitalisation for burns. For the burn cohort, the median length of hospital stay for nervous system conditions was 1 day (IQR 1-3) and for the uninjured cohort, 1 day (IQR 1-2).

Unadjusted rates of admissions and summed length of stay are shown in figure 1; rates of nervous system admissions and time spent in hospital with nervous system conditions were higher for those who had a burn injury when compared with uninjured controls.

After adjusting for demographic-based characteristics along with pre-existing health status, those hospitalised for a burn injury had over twice as many hospital admissions for a nervous system condition (IRR, 95\% CI: 2.20, 1.86 to 2.61), and spent over three times as long in hospital (IRR, 95\% CI: 3.25, 2.28 to 4.64). Subcohort analyses by decade of admission, adjusting for follow-up time, identified increased nervous system admissions for the burn cohort for each time period: 1980-1989 (IRR, 95\% CI: $2.53,1.90$ to 3.35 ); 1990-1999 (IRR, 95\% CI: 2.28, 1.72 to 3.01); 2000-2012: (IRR, 95\% CI: $1.60,1.27$ to 2.00). This increase was found for those younger than 15 years (IRR, 95\% CI: $1.97,1.49$ to 2.61 ), $15-45$ years (IRR, 95\% CI: 2.70, 2.06 to 3.55) and for those 45 years and older (IRR, $95 \%$ CI: $1.62,1.33$ to 1.97 ) at the time of burn injury. The increase was consistent when looking at gender-specific analyses (men-IRR, 95\% CI: 2.26, 1.81 to 2.83 ; women-IRR, $95 \%$ CI: $2.17,1.76$ to 2.67 ).
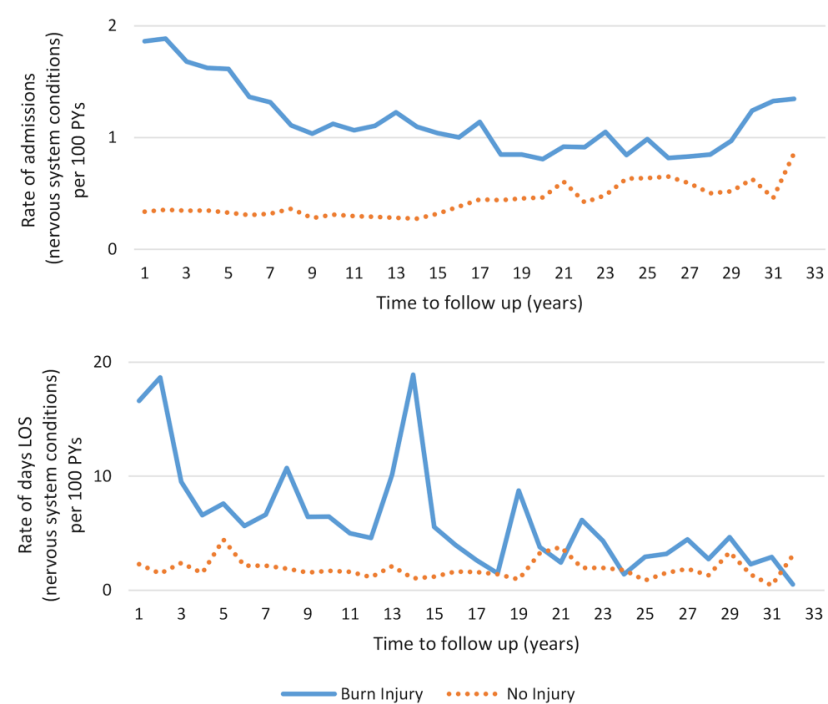

Figure 1 Unadjusted rates of hospital admissions and cumulative LOS (per $100 \mathrm{PYs}$ ) for nervous system conditions comparing those with burn injury (combined severity) versus no injury. LOS, length of stay; PY, person-year. 

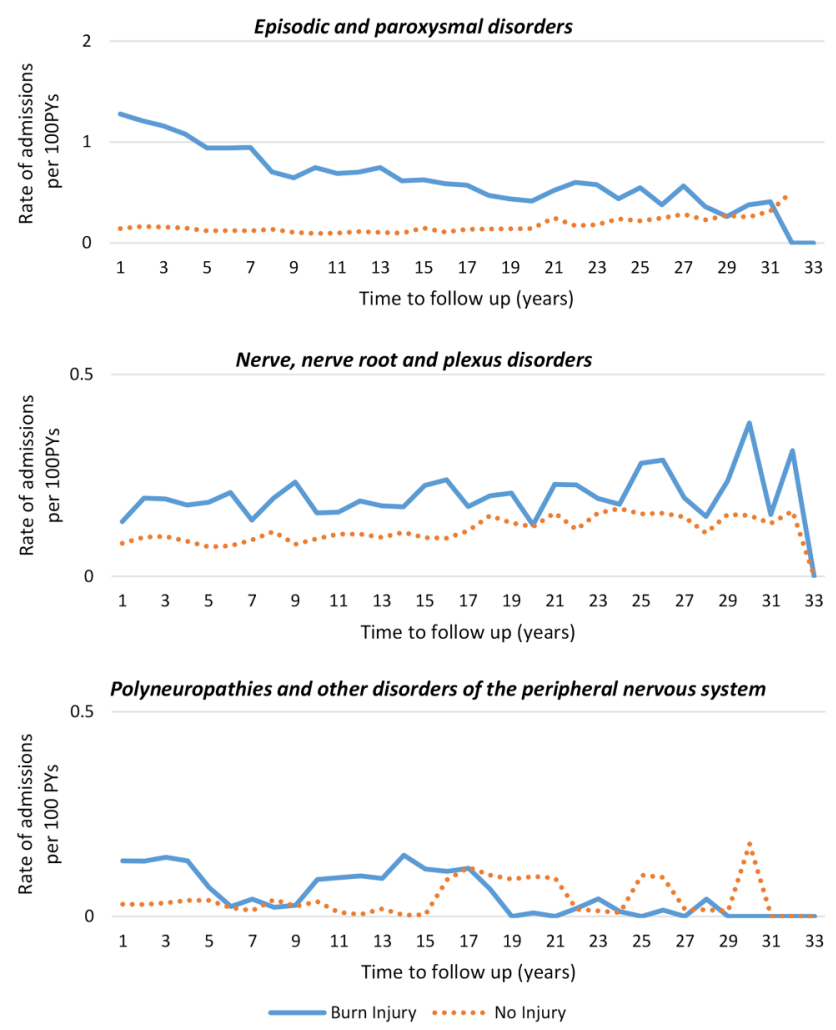

Figure 2 Unadjusted rates (per $100 \mathrm{PYs}$ ) of hospital admissions for nervous system subconditions among those with burn injury (combined severity) versus no injury. PY, person-year.

Unadjusted rates of admissions for specific nervous system subcategories are shown in figure 2. After controlling for demographic factors and pre-existing health status, the burn cohort had a higher rate of admissions for episodic and paroxysmal disorders (IRR, 95\% CI: $2.15,1.77$ to 2.60 ) and nerve, nerve root and plexus disorders (IRR, 95\% CI: $1.23,1.01$ to 1.49 ). There was no difference in the rate of admissions between the burn and uninjured cohorts for polyneuropathies and other disorders of the peripheral nervous system (IRR, 95\% CI: $1.26,0.44$ to 3.60$)$. A significantly longer time was spent in hospital with episodic and paroxysmal disorders (IRR, 95\% CI: 2.83, 1.96 to 4.10); nerve, nerve root and plexus disorders (IRR, 95\% CI: 3.69, 2.17 to 6.28 ); and polyneuropathies and other disorders of the peripheral nervous system (IRR, 95\% CI: 17.30, 5.32 to 56.25). Analysis by TBSA classification (table 3) shows increased admission rates occurring for those with severe, minor and unspecified TBSA burns.

Adjusted analyses excluding those in the burn cohort with burns of unspecified depth and erythema-only (firstdegree) burns also showed increased postburn nervous system admissions (IRR, 95\% CI: 1.96, 1.64 to 2.34 ).

\section{Incidence-survival analysis}

Survival analysis until first nervous system admission was performed on the cohorts excluding those with a previous admission for a nervous system condition, and also excluding those in the burn cohort with a record of a non-burn injury admission. The burn cohort comprised 19741 members and 931 incident nervous system admissions were identified. The uninjured cohort comprised 121925 individuals and 4224 incident nervous system admissions were identified.

Adjusted Cox regression analyses showed significantly elevated incident admission rates for the first 15 years after burn discharge, with higher rates observed for the first 5 years. Refer to table 4 for summary results of multivariate Cox regression analyses. Significant results were observed for 15 years postburn for male and female members of the burn cohort, as well as those younger than 45 years at the time of their burn admission. For adults 45 years and older, significantly elevated incident admission rates were observed for the first 5 years only. Those with minor burns and burns of unknown TBSA had significantly increased admission rates for 15 years postburn. The elevated admission rates for severe burns for the first 5 years postburn did not reach statistical significance.

The burn cohort (total) had a significantly higher rate of first-time admissions over the first 15 years after discharge for episodic and paroxysmal disorders (HR, 95\% CI: $0-5$ years: $2.00,1.69$ to $2.36 ; 5-15$ years: 1.58 , 1.33 to 1.88 ) and for nerve, nerve root and plexus disorders (HR, 95\% CI: $0-5$ years: $1.73,1.38$ to 2.16 ; 5-15 years: $1.34,1.09$ to 1.64$)$. However, the elevated rate for incident admissions for polyneuropathies and other disorders of the peripheral nervous system (HR, 95\% CI:

Table 3 Adjusted IRRs and 95\% Cls for recurrent admissions for NS subconditions, by burn severity versus no injury

\begin{tabular}{|c|c|c|c|}
\hline NS condition & $\begin{array}{l}\text { Severe burns }{ }^{*} \\
\text { IRR }(95 \% \mathrm{Cl}) \dagger\end{array}$ & $\begin{array}{l}\text { Minor burns* } \\
\text { IRR }(95 \% \mathrm{Cl}) \dagger\end{array}$ & $\begin{array}{l}\text { Unspecified severity* } \\
\text { IRR }(95 \% \mathrm{Cl}) \dagger\end{array}$ \\
\hline All NS conditions & $1.43(1.05$ to 1.95$)$ & 2.04 (1.67 to 2.49 ) & 2.39 (1.89 to 3.02$)$ \\
\hline Episodic and paroxysmal disorders & 1.48 (1.02 to 2.16$)$ & 2.53 (2.14 to 2.99$)$ & 2.66 (2.25 to 3.14$)$ \\
\hline Nerve, nerve root and plexus disorders & 2.09 (1.26 to 3.46$)$ & $1.64(1.30$ to 2.05$)$ & 2.04 (1.77 to 2.35$)$ \\
\hline Polyneuropathies, peripheral NS disorders & No admissions & $0.62(0.17$ to 2.27$)$ & 4.69 (1.03 to 21.37$)$ \\
\hline
\end{tabular}

*Severe burns: $\geq 20 \%$ TBSA; minor burns: $<20 \%$ TBSA; unspecified: no TBSA ICD code.

†All models adjusted for sociodemographic (age, gender, aboriginality, social disadvantage, remoteness), index year and health factors (comorbidity, record of prior nervous system condition).

ICD, International Classification of Diseases; IRR, incident rate ratio; NS, nervous system; TBSA, total body surface area. 
Table 4 Adjusted HRs and 95\% Cls for incident admissions for nervous system diseases (combined) after burn discharge, burn compared with uninjured cohort

\begin{tabular}{|c|c|c|}
\hline & $\begin{array}{l}0-5 \text { years } \\
\text { Postburn } \\
\text { HR }(95 \% \mathrm{Cl})^{*}\end{array}$ & $\begin{array}{l}\text { 5-15 years } \\
\text { Postburn } \\
\text { HR }(95 \% \mathrm{Cl})^{\star}\end{array}$ \\
\hline $\begin{array}{l}\text { Total cohort } \\
\text { Gender }\end{array}$ & 1.97 (1.75 to 2.22$)$ & $1.44(1.28$ to 1.63$)$ \\
\hline Men & 1.88 (1.61 to 2.19$)$ & $1.36(1.16$ to 1.58$)$ \\
\hline Women & $2.14(1.76$ to 2.61$)$ & 1.59 (1.31 to 1.94$)$ \\
\hline \multicolumn{3}{|c|}{ Age group (years) } \\
\hline$<15$ & $1.61(1.26$ to 2.05$)$ & 1.53 (1.14 to 2.05$)$ \\
\hline $15-45$ & 2.40 (1.96 to 2.94$)$ & 1.68 (1.41 to 1.99$)$ \\
\hline$\geq 45$ & 1.72 (1.42 to 2.09$)$ & $1.14(0.92$ to 1.42$)$ \\
\hline \multicolumn{3}{|l|}{ TBSA severity } \\
\hline$<20 \%$ minor & 1.85 (1.59 to 2.15$)$ & $1.50(1.25$ to 1.79$)$ \\
\hline$\geq 20 \%$ severe & $1.68(0.97$ to 2.91$)$ & $0.70(0.35$ to 1.40$)$ \\
\hline Unspecified & 2.13 (1.78 to 2.56$)$ & $1.47(1.25$ to 1.73$)$ \\
\hline \multicolumn{3}{|c|}{$\begin{array}{l}\text { *All models adjusted for sociodemographic (age, gender, } \\
\text { indigenous status, social disadvantage, remoteness), index year } \\
\text { and health factors (comorbidity, record of prior nervous system } \\
\text { condition). } \\
\text { TBSA, total body surface area. }\end{array}$} \\
\hline
\end{tabular}

$1.57,0.92$ to 2.67 ) did not reach statistical significance. In total, 290 first-time admissions for a nervous system disorder were attributable to burn injury.

\section{DISCUSSION}

This paper provides a comprehensive population-based assessment of hospital admissions for nervous system conditions experienced by burn patients after discharge for their initial burn injury. While hospital admissions data represent the more serious presentations of morbidity, the study found that after adjustment for sociodemographic and health factors, people with a burn injury sufficiently serious to require hospitalisation experienced twice the admissions (combined incident and prevalent) and spent three times longer in hospital for nervous system conditions, when compared with people with no record of an injury admission. Survival analyses have shown significantly elevated incident or first-time admissions for nervous system conditions for the first 5 years postburn, with those younger than 45 years of age at the time of burn experiencing elevated rate of first-time admissions for a period of 15 years after burn discharge. Admissions for episodic and paroxysmal disorders were the most common, representing $62 \%$ of admissions, followed by $15 \%$ of admissions for disorders of the nerve, the nerve root and plexus and $6 \%$ for polyneuropathies and peripheral disorders.

Severe burns have been shown to cause cerebral changes ${ }^{34}$ with CNS involvement demonstrated following acute peripheral insults to the body such as sepsis, surgery and organ injury. ${ }^{35}$ CNS inflammatory responses have also been demonstrated subsequent to severe burns $\left(\geq\right.$ TBSA20\%). ${ }^{36}{ }^{37}$ Recent animal $^{38} 39$ and in vitro research $^{40}$ have shown that cytokines can directly induce dysfunction of the blood-brain barrier that can lead to burn injury-induced neuroinflammatory changes and neuron damage. ${ }^{34}$ The systemic inflammation triggered by severe burn injury and persistence of hypercortisolic state for up to 3 years after injury ${ }^{41}$ has been postulated to lead to loss of cytoprotective mechanisms and cognitive decline ${ }^{42}$ and could be a common aetiology for the observed changes in the central and peripheral nervous system. Superficial burns, although involving only the epidermis, initiate a significant inflammatory response and neuronal signalling (as evidenced by the accompanying substantial pain). Currently, the mediators that cause increased neurological disorders after burns are unknown; however, there is the potential for inflammatory and/or neuronal-mediated mechanisms to stimulate changes to peripheral nerves, even after superficial injury.

The group of admissions for episodic and paroxysmal disorders comprised admissions for seizures, migraine and other headache symptoms, sleep disorders and transient ischaemic attacks. The high number of postburn admissions for epilepsy and recurrent seizures was an interesting finding. While it is difficult to ascertain from the health administrative data if a burn was secondary to an epileptic seizure, the results showed a persistence of nervous system effects after discharge. However, decompensation of epilepsy had been noted in the acute injury phase after a burn. Decreased protein binding of phenytoin, resulting in enhanced excretion, coupled with hypermetabolism has been proposed as a causative factor. ${ }^{43}$ Although the case report by Gragnani and colleagues depicts acute decompensation after burn injury, long-term effects of burn injury on epilepsy/seizure disorders observed in our study could be explained by the hypermetabolic and inflammatory response persisting for up to 3 years after severe burn injury. ${ }^{41}$ Urinary epinephrine, norepinephrine, cortisol, serum cortisol, granulocyte-macrophage colony-stimulating factor (GM-CSF), interferon gamma (IFN- $\gamma$ ), TNF- $\alpha$,IL-1b, IL-2, IL-5, IL-7, IL-10 and IL-17 were all found to be elevated in this study and cortisol, 11-deoxy cortisol and dehydroepiandrosterone sulfate have all been shown to be proconvulsant in animal models. ${ }^{44}$ Many other factors may also be important, including altered liver and kidney function and/or increased postburn use of antidepressants that can increase seizure risk. ${ }^{41}{ }^{45-47}$ The data here strongly support further investigation into the cause of this increased incidence of seizure admissions postburn.

The elevated admission rate observed for polyneuropathies and other peripheral nervous system disorders experienced by the burn cohort did not reach statistical significance. Peripheral neuropathy in burn patients has been observed to be between $2 \%$ and $82 \%,{ }^{12} 4849$ with mononeuropathies/mononeuritis being identified as the most common presentation. ${ }^{14}$ Polyneuropathy has been described to be more common in full-thickness burns, where the TBSA $>15 \%$ and when the initial length of stay is more than 20 days, suggesting polyneuropathy is predominantly a result of more severe injuries. ${ }^{13}{ }^{15}$ In this 
study, we found a marginal increase in admissions for mononeuropathies (other mononeuropathies). Admissions for polyneuropathies were less common and may be related to the fact that a large proportion of the patients had minor burns (48\%).

A clear burn severity 'dose-response' was not observed. This may in part be due to the small number of those with severe burns in this patient population and/or a 'healthy' survivor effect. An additional possibility is that survivors of severe burns received prolonged postburn care that resulted in earlier diagnoses and management of secondary pathologies, and reduced postburn admissions.

\section{Strengths and limitations}

This large population-based study of linked hospital and death records with long follow-up and a comparison to an uninjured cohort has provided comparative data on the long-term health effects on the nervous system experienced by those with burns. Such data are currently absent from the published literature. The results were adjusted for sociodemographic and pre-existing health status. The social disadvantage variable included in the models has demonstrated high correlation with lifestyle risk factors (including alcohol, smoking, substance abuse, diet and activity). ${ }^{50}$ Hospital data characteristically represent the more serious of diseases requiring admission for assessment and/or management, and the results of this study may under-represent conditions experienced by burn patients that are managed successfully by primary care. Future work that includes a non-burn trauma cohort will assist in the understanding and identification of burn injury-specific mechanisms. Linkage of pharmaceutical and or primary care data with hospital morbidity data would strengthen our ability to identify patients at greatest risk of secondary pathologies of the nervous system and optimal treatment pathways to mitigate such effects. The results of this study would be applicable to other countries of comparable demographic structure and healthcare systems.

\section{CONCLUSIONS}

After adjustment for sociodemographic and health status variables, when compared with a population-based random sample of people with no record of injury admission, those with a record of burn injury requiring hospitalisation, experienced significantly increased longterm nervous system morbidity, in terms of hospital admissions and length of stay. Our findings of increased hospital service use for CNS and peripheral nervous system morbidities support further investigation into the causes underlying this morbidity and possible strategies to ameliorate these long-term health problems.

Acknowledgements The authors thank the staff of the Health Information Linkage Branch for access to the Western Australian Data Linkage System and for their assistance in obtaining the data, the WA Health Data Custodians for access to the core health datasets and the Western Australian Department of
Health. The project was supported by the Raine Medical Research Foundation (Priming grant JMD). JMD is supported by Woodside Corporation. MWF is supported by Chevron Australia.

Contributors All authors have made contributions to the paper and have authorised the submission. TPV contributed clinical interpretation of results and drafted the manuscript. JMD designed the study, supported data analyses and interpretation and supported manuscript preparation. SMR and JHB provided data management, analyses and data interpretation. MWF, SMR and FMW contributed clinical interpretation. All authors contributed to manuscript preparation and critical revision.

Funding Project data costs were supported by a Raine Medical Research Foundation Priming grant and Woodside corporate sponsorship via the Fiona Wood Foundation.

\section{Competing interests None declared.}

Ethics approval This study has received ethics approval from the University of Western Australia and the Western Australian Department of Health. Being a large population cohort study using de-identified linked data, approval included a waiver of informed consent.

Provenance and peer review Not commissioned; externally peer reviewed.

Data sharing statement No additional data are available.

Open Access This is an Open Access article distributed in accordance with the Creative Commons Attribution Non Commercial (CC BY-NC 4.0) license, which permits others to distribute, remix, adapt, build upon this work noncommercially, and license their derivative works on different terms, provided the original work is properly cited and the use is non-commercial. See: http:// creativecommons.org/licenses/by-nc/4.0/

\section{REFERENCES}

1. Anderson JR, Zorbas JS, Phillips JK, et al. Systemic decreases in cutaneous innervation after burn injury. J Invest Dermatol 2010;130:1948-51.

2. Ward RS, Tuckett RP, English KB, et al. Substance P axons and sensory threshold increase in burn-graft human skin. J Surg Res 2004;118:154-60.

3. Chang YW, Tan A, Saab C, et al. Unilateral focal burn injury is followed by long-lasting bilateral allodynia and neuronal hyperexcitability in spinal cord dorsal horn. J Pain 2010;11:119-30.

4. Wu SH, Huang SH, Cheng KI, et al. Third-degree hindpaw burn injury induced apoptosis of lumbar spinal cord ventral horn motor neurons and sciatic nerve and muscle atrophy in rats. Biomed Res Int 2015;2015:372819.

5. Ji Q, Jia $H$, Dai $H$, et al. Protective effects of pentoxifylline on the brain following remote burn injury. Burns 2010;36:1300-8.

6. Malenfant A, Forget R, Amsel R, et al. Tactile, thermal and pain sensibility in burned patients with and without chronic pain and paresthesia problems. Pain 1998;77:241-51.

7. Choinière M, Melzack R, Papillon J. Pain and paresthesia in patients with healed burns: an exploratory study. J Pain Symptom Manage 1991;6:437-44.

8. Dauber A, Osgood PF, Breslau AJ, et al. Chronic persistent pain after severe burns: a survey of 358 burn survivors. Pain Med 2002;3:6-17.

9. Melzack R, Coderre TJ, Katz J, et al. Central neuroplasticity and pathological pain. Ann N Y Acad Sci 2001;933:157-74.

10. Helm PA, Johnson ER, Mclntosh Carlton A. Peripheral neurological problems in the acute burn patient. Burns 1977;3:123-5.

11. Henderson B, Koepke GH, Feller I. Peripheral polyneuropathy among patients with burns. Arch Phys Med Rehabil 1971;52:149-51.

12. Marquez S, Turley JJ, Peters WJ. Neuropathy in burn patients. Brain 1993;116(Pt 2):471-83.

13. Tamam $\mathrm{Y}$, Tamam $\mathrm{C}$, Tamam $\mathrm{B}$, et al. Peripheral neuropathy after burn injury. Eur Rev Med Pharmacol Sci 2013;17(Suppl 1):107-11.

14. Gabriel V, Kowalske KJ, Holavanahalli RK. Assessment of recovery from burn-related neuropathy by electrodiagnostic testing. J Burn Care Res 2009;30:668-74.

15. Kowalske K, Holavanahalli R, Helm P. Neuropathy after burn injury. J Burn Care Rehabil 2001;22:353-7.

16. Calvano TP, Hospenthal DR, Renz EM, et al. Central nervous system infections in patients with severe burns. Burns 2010;36:688-91. 
17. Winkelman MD, Galloway PG. Central nervous system complications of thermal burns. A postmortem study of 139 patients. Medicine 1992;71:271-83.

18. Holman CDJ, Bass AJ, Rouse IL, et al. Population-based linkage of health records in Western Australia: development of a health service research linked database. Aust N Z J Public Health 1999;23:453-9.

19. Department of Health Western Australia. Clinical Information Audit Program-Hospital Activity Report. Operational Directive OD 0201/ 09. Perth Department of Health WA, 2009.

20. Duke JM, Boyd JH, Rea S, et al. Long-term mortality among older adults with burn injury: a population-based study in Australia. Bull World Health Organ 2015;93:400-6.

21. Duke JM, Randall SM, Fear MW, et al. Understanding the long-term impacts of burn on the cardiovascular system. Burns 2016;42:366-74.

22. Duke JM, Rea S, Boyd JH, et al. Mortality after burn injury in children: a 33 year population-based study. Pediatrics 2015;135: e903-10.

23. Trewin D. Socio-economic indexes for areas (Information Paper, Census of Population and Housing). Canberra: Australian Bureau of Statistics, 2003.

24. Glover J, Tennant S. Remote areas statistical geography in Australia: notes on the Accessibility/Remoteness Index for Australia (ARIA+version). Working Papers Series No. 9. Adelaide: Public Health Information Development Unit, Adelaide, The University of Adelaide, 2003.

25. Charlson ME, Pompei P, Ales KL, et al. A new method of classifying prognostic comorbidity in longitudinal studies: development and validation. J Chronic Dis 1987;40:373-83.

26. Preen DB, Holman CDAJ, Spilsbury K, et al. Length of comorbidity lookback period affected regression model performance of administrative health data. J Clin Epidemiol 2006;59:940-6.

27. National Centre for Classification in Health. Australian Consortium for Classification Development. Secondary Australian Consortium for Classification Development. https://www.accd.net.au/

28. Valvis SM, Waithman J, Wood FM, et al. The immune response to skin trauma is dependent on the etiology of injury in a mouse mode of burn and excision. J Invest Dermatol 2015;135:2119-28.

29. Hosmer DW, Lemeshow S. Applied survival analysis: regression modeling of time to event data. New York: Wiley, 1999.

30. Hosmer DW, Royston P. Using Aalen's linear hazards model to investigate time-varying effects in the proportional hazards regression model. Stata J 2002;2:331-50.

31. Gordis L. Epidemiology. 2nd edn. Philadelphia: WB: Saunders Company, 2000.

32. Cameron CM, Purdie DM, Kliewer EV, et al. Long-term mortality following trauma: 10 year follow-up in a population-based sample of injured adults. J Trauma 2005;59:639-46.

33. Duke JM, Boyd JH, Randall SM, et al. Long term mortality in a population-based cohort of adolescents, and young and middle-aged adults with burn injury in Western Australia: a 33-year study. Accid Anal Prev 2015;85:118-24.

34. Flierl MA, Stahel PF, Touban BM, et al. Bench-to-bedside review: burn-induced cerebral inflammation-a neglected entity? Crit Care2009;13:215.

35. Fung A, Vizcaychipi M, Lloyd D, et al. Central nervous system inflammation in disease related conditions: mechanistic prospects. Brain Res 2012;1446:144-55.

36. Agay D, Andriollo-Sanchez M, Claeyssen R, et al. Interleukin-6, TNF-alpha and interleukin-1 beta levels in blood and tissue in severely burned rats. Eur Cytokine Netw 2008;19:1-7.

37. Reyes $\mathrm{R} \mathrm{Jr}, \mathrm{Wu} \mathrm{Y}$, Lai $\mathrm{Q}$, et al. Early inflammatory response in rat brain after peripheral thermal injury. Neurosci Lett 2006;407:11-15.

38. Berger J, Sprague SM, Wu Y, et al. Peripheral thermal injury causes early blood-brain barrier dysfunction and matrix metalloproteinase expression in rat. Neurol Res 2007;29:610-14.

39. Pan W, Hsuchou H, Yu C, et al. Permeation of blood-borne IL15 across the blood-brain barrier and the effect of LPS. J Neurochem 2008;106:313-19.

40. de Vries HE, Blom-Roosemalen MC, van Oosten M, et al. The influence of cytokines on the integrity of the blood-brain barrier in vitro. J Neuroimmunol 1996;64:37-43.

41. Jeschke MG, Gauglitz GG, Kulp GA, et al. Long-term persistence of the pathophysiologic response to severe burn injury. PLOS ONE 2011;6:e21245.

42. Vizcaychipi MP, Lloyd DG, Wan Y, et al. Xenon pretreatment may prevent early memory decline after isoflurane anesthesia and surgery in mice. PLOS ONE 2011;6:e26394.

43. Gragnani A, Müller BR, Oliveira AF, et al. Burns and epilepsyreview and case report. Burns 2015;41:e15-18.

44. Reddy DS. Role of hormones and neurosteroids in epileptogenesis. Front Cell Neurosci 2013;7:115.

45. Coca SG, Bauling P, Schifftner T, et al. Contribution of acute kidney injury toward morbidity and mortality in burns: a contemporary analysis. Am J Kidney Dis 2007;49:517-23.

46. Bloechliger M, Ceschi A, Kupferschmidt $\mathrm{H}$, et a/Risk of seizures associated with antidepressant use in patients with depressive disorder: follow-up study with a nested case-control analysis using the clinical practice research datalink. Drug Saf 2016;39:307-21.

47. Bloechliger M, Rüegg S, Jick SS, et al. Antipsychotic drug use and the risk of seizures: follow-up study with a nested case-control analysis. CNS Drugs 2015;29:591-603.

48. Helm PA, Pandian G, Heck E. Neuromuscular problems in the burn patient: cause and prevention. Arch Phys Med Rehabil 1985;66:451-3.

49. Monafo WW, Eliasson SG. Sciatic nerve function following hindlimb thermal injury. J Surg Res 1987;43:344-50.

50. Taylor AW, Dal Grande E, Wu J, et al. Ten-year trends in major lifestyle risk factors using an ongoing population surveillance system in Australia. Popul Health Metri 2014;12:31. 